\title{
Mainz ii pouch for urinary diversion: outcome and quality of life among patients who underwent it at CCBRT hospital dar es salaam 20 I I/20 I3
}

\begin{abstract}
Introduction: Obstetric fistula is the result of prolonged, obstructed labor. Each year 50,000-100,000 women affected worldwide. An estimated 2 million women live with untreated fistula in Sub-Saharan Africa and Asia. Approximately 3,700 new cases of obstetric fistula occur in Tanzania yearly but, only about 1,000 get treated. CCBRT is a specialized hospital \& biggest center for obstetric fistula in Tanzania with the main objective to treat and attain continence to these patients.
\end{abstract}

Rationale: Different forms of urinary diversions exist, each with its own advantages \& disadvantages. MAINZ II pouch involves a permanent lifestyle change in normal micturition habit, though it's associated with acidosis, night time incontinence, pyelonephritis and malignancies.

Objectives: Assessing the outcome with emphasis on the complications and quality of life of patients who underwent MAINZ II pouch urinary diversion at CCBRT hospital during 2011-13.

\section{Methods:}
i. Inclusion criteria: Patients who consented and underwent the procedure.
ii. Followed up: Physical visits and phone calls,
iii. Documentation: Checklist designed to fill-in the variables of interest.
iv. Duration: 6 to 24 months post-surgery.

Results:

a. 10 patients were followed up effectively, 7 out of $10(70 \%)$ were completely continent through day and night.

b. $2(20 \%)$ were incontinent during the night

c. $1(10 \%)$ was incontinent through day and night

d. 2 patients experienced recurrent flank pain with fever and responding to antibiotics

e. $8(80 \%)$ had no symptoms of pyelonephritis.

f. $90 \%$ of patients resumed full daily physical activities with improved social life.

g. Socialization improved for those with incontinency as it's less severe compared to pre-operatively.

Conclusion: MAINZE II procedure demonstrated good outcome in terms of continence, less complications resulting improved quality of life to patients.

Recommendations: Procedure recommended to patients with irreparable obstetric fistula.
Volume 4 Issue 4 - 2016

Vindhya Pathirana, Majinge P, Chapa JP

CCBRT disability hospital,Tanzania

Correspondence: Vindhya Pathirana, Head of VVF Department, Comprehensive Community Based Rehabilitation in Tanzania Disability Hospital, Dar es Salaam, Box 106139, Tanzania,Tel 255758720627,Email drvindhya.p@gmail.com

Received: October 28, 2015 | Published: April 14, 2016

\section{Introduction and literature review}

Obstetric fistula is the result of prolonged, obstructed labor. It affects between 50,000 to 100,000 women worldwide each year. It is estimated that around 2

million women live with untreated fistula in sub-Saharan Africa and Asia. An estimated 3,700 new cases of obstetric fistula occur in Tanzania every year, but only about 1,000 get treated. ${ }^{1}$ Women with obstetric fistula often suffer from physical, social and psychological consequences.
A fistula can be simple or complex. A classification of simple or complex fistula is determined by the size of the fistula, involvement of the continence mechanism and the degree of scarring. The size greater than $4 \mathrm{~cm}$, urethral involvement and moderate or severe scarring constitute features of complex fistula. ${ }^{2}$. Obstetric fistulas are rarely simple. Majority of simple fistulas are successfully repaired vaginally. Some women with vesico-vaginal fistulas (VVF) have injuries so severe that they cannot be repaired in a way that would restore continence. ${ }^{3}$

In majority of cases, the irreparability is caused by multiple factors like failed previous repairs, damaged urethra, a small bladder with 
loss of bladder tissue and severe fibrosis. For such patients there are only two options: Do nothing or perform some form of urinary diversions. ${ }^{4}$ The diversions are broadly categorized into conduit and continent diversions. The Mainz II is reportedly associated with fewer complications than classic ureterosigmoidostomy and with acceptable health-related quality of life. The hallmark of the Mainz Pouch II procedure is the detubularization of the sigmoid colon to provide a lower-pressure. ${ }^{5}$ Low pressure colonic pouch MAINZE II surgery for urinary diversion is however associated with acidosis, night-time incontinence and infection.

\section{Problem statement and rationale}

There is no enough data regarding the safety and quality of life after urinary diversion using modified ureterosigmoidostomy in developing countries. This study aimed at adding to the available data, the safety and quality of life with regards to Mainz II pouch urinary diversion. It looked into the outcome of this type of diversion with emphasis on assessing the complications and how the procedure and its outcome affect quality of life to patients who underwent the procedure.

\section{Objectives}

\section{Main objective}

To assess the outcome and the quality of life among patient who underwent MAINZE II pouch urinary diversion procedure at CCBRT hospital.

\section{Specific objectives}

i. To assess the outcome of Mainz II procedure

ii. To assess the quality of life among patients who underwent Mainz II pouch procedure.

\section{Methodology}

\section{Study design}

It was a cross-sectional study looking at the outcome in terms of complication and achievement of continence and the quality of life to patients post MAINZ II pouch diversion.

\section{Study population}

All patients who underwent urinary diversion.

\section{Study area \\ CCBRT hospital}

It is a comprehensive Community Based Rehabilitation in Tanzania (CCBRT) that was established as a Community Based Rehabilitation programme searching for people with cataract in Dar es Salaam. Since then it has grown to become the largest indigenous provider of disability services in Tanzania. It is locally registered NGO aiming to empower people with disabilities and their families, improve their quality of life, and ensure access to medical and rehabilitative treatment. It now one of the biggest centres in the country dealing with fistula repairs. The fistula wards have 70 beds capacity, the number of repairs increase by year, last year only; more than 500 patients were treated for fistula.

\section{Study period} 2013.

The study used data collected between January 2011 to March,

\section{Sample size}

Convenience sampling method was used. All patients who were available during study period were included in the sample.

\section{Data collection and processing}

The data were collected from records of follow up of patients after surgery. The follow up was done through physical visits and phone calls, their progress were documented. A checklist was designed to fill-in the variables of interest. All patients who had MAINZE II diversion and consented to participate were included in the study. The included patients had a follow up of 6 to 24 months post surgery. The data were then cleaned and manually analyzed.

\section{Operational definitions}

\section{Good outcome}

a. Minimal or no postoperative complications

b. Achievement of continence

Continence: Means being able to voluntarily pass stool and hence completely dry.

Quality of life: The ability to resume their routine physical and social activities with health mind.

\section{Results}

25 patients underwent urinary diversion during the study period, but we managed to follow up 10 patients effectively, the follow up was difficult because majority of patients are coming from very remote areas with difficult communications and reach.

i. Seven out of ten $(70 \%)$ were completely continent during the day and night. $3(30 \%)$ were incontinent during the night and $1(10 \%)$ was incontinent both during the day and night.

ii. Two patients experienced recurrent flank pain with fever that has been responding to antibiotics. The majority of patients i.e. $8(80 \%)$, had no symptoms of pyelonephritis.

iii. Ninety percent $(90 \%)$ of our patients resumed their daily physical activities.

iv. All the patients were participating in social activities that couldn't participate before surgery.

v. All the patients admitted to have happy and satisfied life now after surgery. (Table $1 \& 2$ ).

Table I Comparison of day and night continence pattern among study participants

\begin{tabular}{lllll}
\hline Continence & Day & \multicolumn{3}{l}{ Night } \\
& Yes & No & Yes & No \\
\hline Number of patients & $9(90 \%)$ & $1(10 \%)$ & $7(70 \%)$ & $3(30 \%)$ \\
Total & 10 & & 10 & \\
\hline
\end{tabular}

\section{Conclusion}

MAINZE II procedure has shown to have good outcome in terms of continence with less complications resulting into improving quality of life to patients.

\section{Recommendations}

a. We would recommend this procedure to patients with irreparable obstetric fistula.

b. A study with large sample should be conducted. 
Table 2 Comparison of other activities among study participants

\begin{tabular}{|c|c|c|c|c|c|c|c|c|c|}
\hline \multirow[t]{2}{*}{ QoL } & \multirow{2}{*}{$\begin{array}{l}\text { Physical activity } \\
\text { Normal impaired }\end{array}$} & \multicolumn{2}{|c|}{$\begin{array}{l}\text { Going out for social } \\
\text { gatherings }\end{array}$} & \multicolumn{2}{|c|}{$\begin{array}{l}\text { Relationship with close } \\
\text { relatives }\end{array}$} & \multicolumn{2}{|c|}{$\begin{array}{l}\text { Happy and } \\
\text { satisfied }\end{array}$} & \multicolumn{2}{|c|}{ Hopeless } \\
\hline & & Yes & No & Yes & No & Yes & No & Yes & No \\
\hline Number (\%) & 9 & 10 & 0 & 10 & 0 & 10 & 0 & 0 & 10 \\
\hline Total & 10 & 10 & & 10 & & 10 & & 10 & \\
\hline
\end{tabular}

\section{Acknowledgments}

None.

\section{Conflicts of interest}

None.

\section{References}

1. United Nations Population Fund.

2. Genadry RR, Creanga AA, Roenneburg ML, et al. Complex obstetric fistulas. Int J Gynaecol Obstet. 2007;99 Supp11:S51-S56.
3. Arrowsmith SD. Urinary diversion in the vesico-vaginal fistula patient: general considerations regarding feasibility, safety, and follow-up. Int $J$ Gynaecol Obstet. 2007;99Supp11:S65-S68.

4. Sulabha Joshi, Anuja Bhalerao, Savita Somalwar, et al. A rare case of irreparable vesico-vaginal fistula of 45 years duration successfully managed by urinary diversion. J Midlife Health. 2011;2(1):37-39.

5. Gutman RE, Dodson JL, Mostwin JL. Complications of treatment of obstetric fistula in the developing world. Int $J$ Gynaecol Obstet. 2007;99Supp11:S57-S64 